\author{
Klaus Wuttich
}

\title{
ARE THE FUTURE AND THE PAST REALLY OPACITY-CREATING OPERATORS?
}

\author{
CONTENTS
}

1. The myth of „intensional” or "opaque” contexts

2. Are there criteria of "Intensionality”?

3. The future tense and "Referential Opacity"

4. The past tense and „Intensionality"

5. The substitution principle remains valid 


\section{The myth of ,intensional" or „opaque" contexts}

Among logicians there exists the widely accepted view that classical logic as developed by Frege, Russell, Peano, Peirce and others is not able to master all the problems arising in connection with indirect speech and similar phenomena. There is a myth that classical or so-called extensional logic is good only for one part of our language, for extensional contexts, while a large area of our language, consisting of intensional or opaque contexts, needs a special, non-extensional or intensional logic. It is obvious that this point of view denies the universality of logic and logical rules.

Elsewhere (cf. Wuttich (1995a, 1995b)) I tried to show the origins of talk about so-called intensional propositions, functions or contexts, and the reason for the genesis of this manner of speech. There one can find also an analysis of several attempts by logicians to find arguments against the interpretation of certain sentences as intensional.

Recently H. Wessel made interesting proposals about how to analyze an important class of ,intensional” sentences, sentences which contain so-called that-clauses (cf. Wessel (1995a, 1995b)). He introduced new term-forming operators to enrich his Theory of Terms. ${ }^{1}$ With the help of these new logical means he is able to show that no problem of "Intensionality" arises when we take into account the real structure of expressions of that kind, that there are no ,intensional contexts" where the substitution rule does not work at all or only in a restricted manner, but that there are only unsatisfactory analyses.

\section{Are there criteria of „Intensionality"?}

The use of terms like intensional context or intensional proposition involves a lot of problems. One of them consists in finding out which propositions belong to this kind of expression. There is no uniform use of the word intensional. So belief propositions are regarded to be intensional by one author (F. von Kutschera ${ }^{2}$ ) and non-intensional by another (R. Carnap ${ }^{3}$ ), norms

\footnotetext{
1 This theory is described in Wessel (1984).

${ }^{2}$ Cf. Kutschera (1976).

3 Cf. Carnap (1972).
} 
are supposed to be intensional by some logicians (L. Gumański ${ }^{4}$ ) and extensional by others (L. Kreiser ${ }^{5}$ ). We do not find any positive criterion for the definition of 'intensional' but only examples of intensional verbs or expressions (cf. Searle (1983)). Obviously people have difficulty in giving a positive definition of 'intensionality'.

Therefore no wonder people start explaining such notions as 'intensional context' or 'intensional sentence' by explaining the phenomenon of extensionality. Usually extensional expressions are taken to be expressions where the substitution of terms or sentences having the same extension does not lead to complications, and especially does not change the truth-value of the expression obtained by substitution. If there could be a change in the truth-value, the expression is called intensional or non-extensional.

Nevertheless there is at least one common feature of intensional contexts: the failure of substitution of identicals, i.e. of the inference rule that expressions which denote the same object are mutually substitutable salva veritate within sentences. Given this feature, logicians are searching for „intensionality-creating" entities, i.e. for words or operators or predicates which are responsible for the "troubles with extensionality". Entities of this kind seem to be the so-called propositional attitude verbs, among them the group of epistemic verbs (believe, know), certain sentential adverbs (possibly, necessarily), certain verbs with prepositional objects (dream about, look for), and certain direct object verbs (seek, imagine). ${ }^{6}$

The claim that tenses create intensional (opaque) contexts is not frequently made. It can be found in the article Tense as a Source of Intensional Ambiguity $^{7}$ written by Eva Ejerhed in 1980. In this paper the author argues that not only the future modal will in English and its cognates in other languages are intensional, but also that the past tense behaves similarly.

The aim of my paper is to show that the invalidity of the inferences given in the mentioned paper for the sake of demonstrating the opacity-producing character of tenses is simply due to an incorrect formalization. If there is really some opacity, it is home-made. Describing the given situation in a correct way, the myth of "Intensionality" disappears here just as in other cases.

${ }^{4}$ Cf. Kreiser/Gottwald/Stelzner $(1988,259)$.

${ }^{5}$ Cf. Kreiser/Gottwald/Stelzner $(1988,5)$.

6 Of course the search for criteria of "Intensionality" or for ,intensionality-creating" entities does not make sense if one is convinced that there are no „intensional” statements or contexts (cf. Wessel (1995a, 1995b)).

7 Cf. Ejerhed (1980). 
In Ejerhed's opinion the substitution principle

$$
\begin{gathered}
P(a) \\
a=b \\
\hline P(b)
\end{gathered}
$$

is generally valid only in non-complex, simple present or present progressive sentences with extensional verbs. Therefore, in her opinion the following inference based on $(S P)$ must be valid without doubt.

John is looking at the President.

The President is Bill Clinton.

John is looking at Bill Clinton.

If we understand the word 'President' in the second premise as a singular subject term and not as a general one, for example as 'the present President of the USA', we can interpret this sentence as an identity statement. In this case we have no problem, the given inference is valid, the substitution principle works. But the sentence 'The President is Bill Clinton' need not be understood necessarily as an identity statement. Another possibility is to interpret it as 'The name of the President is Bill Clinton' or as a statement about the connection of the meaning of the singular subject terms 'The (present) President (of the USA)' and 'Bill Clinton'. These terms include each other by meaning and therefore have the same meaning. ${ }^{8}$ From the identity $a=b$ follows that the two terms $a$ and $b$ include each other by meaning (formally $t a \rightleftharpoons t b$ ), but not the other way round.

\section{The future tense and "Referential Opacity"}

But let us see what a strange argumentation is possible if somebody believes in the myth of "Intensionality". As an example of failure of substitution due to the future tense alone, Ejerhed considers an inference similar to the following: ${ }^{9}$

1. Castro will meet the President (of the USA).

2. The President (of the USA) is Bill Clinton.

3. Castro will meet Bill Clinton.

\footnotetext{
8 The notion of meaning-inclusion was introduced by A. Sinowjew and H. Wessel, cf. Wessel (1984, 312f.).

${ }^{9}$ I made some small changes by using another person Castro wants to meet, but I did not change the presuppositions made by the author.
} 
The sentence (1) as a whole, and the identity statement (2) are both taken to be true relative to the same time, say September 12, 1995. It is further assumed that the meeting is scheduled to take place in December 1996, after the next election of the President in the USA. Now it can be argued that someone other than Bill Clinton may be the President of the USA at the time of the meeting, if not before (remember John Kennedy!). Hence, (3) is not valid on the reading of (1) in which the definite description refers to the future holder of the office.

As Ejerhed claims, this example (or better: examples of that kind) show that the future tense passes a standardly accepted test for referential opacity, the failure of substitution of identicals. In my opinion there is something wrong with this test. It is not the substitution principle $(S P)$ which is proved to be invalid by Ejerhed, but a totally different rule-like set of sentences. No reasonable woman or man would defend the inference from (1) and (2) to (3), if she or he knows about the presuppositions concerning the time of the meeting and the time of the election.

One could ask: Why Ejerhed did not include her explicitly made presuppositions in the premises and the conclusion? The answer is very easy: Because in that case everybody could see at once that the given inference is not conclusive.

The sentences (1)-(3) should be paraphrazed into:

$1^{\prime}$. Castro will meet the President (of the USA) of the end of the year 1996.

$2^{\prime}$. Bill Clinton is the President (of the USA) in September 1995.

$3^{\prime}$. Castro will meet Bill Clinton.

Translating the sentences $\left(1^{\prime}\right)-\left(3^{\prime}\right)$ into the language of logic we get:

$$
\begin{aligned}
& F(a) \\
& b=c \\
& \hline F(b)
\end{aligned}
$$

This very strange „inference” was not performed by $(S P)$, therefore we cannot blame this logical rule. It is easy to see that the problem with the inference from (1) and (2) to (3) has nothing to do with "Intensionality" or "Referential Opacity". The problem could arise because in these sentences important information was held back. Due to this trick the matter became opaque, though only artificially. The seeming "Intensionality" disappears while describing the situation precisely. 


\section{The past tense and "Intensionality”}

In a similar way Ejerhed tried to demonstrate that the past tense can be responsible for the appearance of "Intensionality", too. ${ }^{10}$ She uses the following example from Lemmon: ${ }^{11}$

4. I flew my spaceship to the Morning Star.

5. The Morning Star is the first planet struck by a man-made missile.

6. I flew my spaceship to the first planet struck by a man-made missile.

As she argues, (4) in conjunction with (5) does not entail (6) on the assumption that the date of the flight precedes the date of the Soviet landing of a missile on Venus. Although (4) and (5) may be true relative to the same point of reference, they are not true at the same time, (4) being true prior to $(5)$.

But again, if we knew about these assumptions, we would not infer (6) from (4) and (5). Why should we?

It is interesting that Lemmon did not see any „Intensionality” in his example. I fully agree with his remark:

Only one principle seems quite safe: If $F(a)$ is true at time $t$, and at the same time $a=b$, then $F(b)$ is true at time $t$. (Ejerhed 1980,234).

Because of the validity of the mentioned principle, we have in classical logic an implicit, tacit assumption, namely that the premises and the conclusion of an inference are true always at the same time. This assumption is usually not mentioned in textbooks of logic. An exception is Horst Wessel's book Logic. The author writes:

Formulating e.g. the logical rule $A \vdash A$ one implicitely assumes the identity of coordinates of both premiss and consequent, i.e. $A \alpha \vdash A \alpha$ (Wessel 1984, 294)

\section{The substitution principle remains valid}

It is obvious now that Ejerhed did not demonstrate with Lemmon's example the invalidity of $(S P)$ in a certain context, for she showed only that the following rule is not valid:

${ }^{10}$ Cf. Jackendoff (1975), Givón (1973), Needham (1975). These authors seem to share Ejerhed's opinion about the „opacity-creating" force of the future tense but not of the past tense.

11 Cf. Lemmon (1966). 


$$
\begin{gathered}
F(a)^{t_{1}} \\
(a=b)^{t_{2}} \\
F(b)^{t_{1} \text { or } t_{2}}
\end{gathered}
$$

where $t_{1}$ and $t_{2}$ are moments of time, $t_{1}$ is earlier than $t_{2}$, and $F(b)^{t_{1}}$ or $t_{2}$ means that $F(b)$ is true at $t_{1}$ or $t_{2}$. The invalidity of $\left(S P^{t}\right)$ is obvious. This can be demonstrated by the following example:

1. Honnecker reigned in Berlin.

2. Berlin is the capital of the FRG.

3. Honnecker reigned in the capital of the FRG.

The premisses are true, but the conclusion is false.

When we use time-intervals instead of moments of time, it becomes clear that we have to demand for the validity of rules like $\left(S P^{t}\right)$ that the time-intervals in which the premisses are true have to intersect each other. This demand was not fulfilled in the latter example because Honnecker's time of reign finished on the $18^{\text {th }}$ of October 1989, and Berlin became the capital of the reunified Germany some months later.

In the next example the mentioned demand is fulfilled, therefore the following inference is valid:

1. Honnecker lived in Berlin.

2. Berlin is the capital of the FRG.

3. Honnecker lived in the capital of the FRG.

for there was a time, at which Honnecker lived in Berlin (-Moabit), and Berlin was already the capital of Germany.

Lemmon's principle could be reformulated according to sentences about the past in the following way:

If $F(a)$ is true at a time-interval $t_{1}$, and if this time-interval intersects with the time-interval $t_{2}$, in which $a=b$ is true, then $F(b)$ is true at the intersection of $t_{1}$ and $t_{2}$.

Again, it is obvious that all this has nothing to do with "Intensionality" or "Opacity". It shows simply that while performing logical inferences we have to keep in mind certain restrictions concerning the time-intervals at which the premises and the conclusion are true, unless we are supposing that all sentences are true at one and the same time.

Ejerhed's claim that the substitution rule proves to be invalid in the given examples is therefore untenable. What fails is not this good old logical rule, but some rule-like sets of sentences as 


$$
\begin{array}{ccc}
F(a)^{t_{1}} & & F(a) \\
(a=b)^{t_{2}} & \text { or } \quad & \frac{b=c}{F(b)}
\end{array}
$$

But no reasonable person would claim that these things are logical rules and that we have to banish them from the realm of logic.

Acknowledgments. The research presented in this paper was supported by the Deutsche Forschungsgemeinschaft (DFG). I would like to thank Karl-Heinz Krampitz and Uwe Scheffler who have made helpful comments on a previous version of this paper.

\section{References}

Carnap, Rudolf, Bedeutung und Notwendigkeit: Eine Studie zur Semantik und modalen Logik, Springer, Wien - New York 1972.

Ejerhed, Eva, „Tense as a Source of Intensional Ambiguity” [in:] Ambiguities in Intensional Contexts, F. Heny (ed.), Reidel, Dordrecht 1980, 231-252.

Givón, Talmy, „Opacity and Reference in Language: An Inquiry into the Role of Modalities" [in:] Syntax and Semantics, 2, J. Kimball (ed.), Academic Press, New York 1973.

Jackendoff, Ray, „On belief-contexts”, Linguistic Inquiry, 6 (1975), 53-93.

Kreiser, Lothar/Gottwald, Siegfried/Stelzner, Werner, Nichtklassische Logik, Akademie-Verlag, Berlin 1988.

Kutschera, Franz von, Einführung in die intensionale Semantik, Walter de Gruyter, Berlin - New York 1976.

Lemmon, E., „Comments on The Logical Form of Action Sentences by Donald Davidson" [in:] The Logic of Decision and Action, N. Rescher (ed.) Pittsburgh 1966.

Needham, Paul, Temporal Perspective. A Logical Analysis of Temporal Reference in English, Philosophical Studies 25, Department of Philosophy, University of Uppsala, Uppsala 1975.

Quine, Willard Van Orman, Wort und Gegenstand, Reclam, Stuttgart 1980.

Searle, John R., Intentionalität: Eine Abhandlung zur Philosophie des Geistes, Suhrkamp, Frankfurt am Main 1987. 
Sinowjew, Alexander/Wessel, Horst, Logische Sprachregeln, Deutscher Verlag der Wissenschaften, Berlin 1975.

Wessel, Horst, Logik, Deutscher Verlag der Wissenschaften, Berlin 1984.

Wessel, Horst (1995a), „Wider den Mythos intensionaler Kontexte, Erscheint” [in:] Analyomen 2.

Wessel, Horst (1995b), „Krippkes Puzzle ist kein Puzzle”. Manuskript.

Wuttich (1995a), „Intensionalität - Entstehung und Kritik eines Mythos”. Manuskript.

Wuttich (1995b), „Intensional Contexts - Genesis and Criticism of a Mythos”, [in:] Volume of Abstracts, $10^{\text {th }}$ International Congress of Logic, Methodology and Philosophy of Science, August 19-25, 1995 - Florence, Italy, Florence, 1995, 192.

Wuttich, Klaus, Glaube, Zweifel, Wissen: Eine logisch-philosophische Studie, Deutscher Verlag der Wissenschaften, Berlin 1991.

\author{
Klaus WutTich \\ Institute of Philosophy \\ Humboldt University \\ Unter den Linden 6 \\ D 10099 Berlin, Germany
}

